\title{
Developing a Master Production Schedule Using Fuzzy Mixed Integer Linear Programming
}

\author{
Mohamed K. Omar ${ }^{\mathrm{a}}$, Muzalna Mohd-Jusoh ${ }^{\mathrm{b}, \mathrm{c}}$, Mohd Omar ${ }^{\mathrm{c}}$ \\ ${ }^{a}$ Nottingham University Business School, University of Nottingham (Malaysia Campus) \\ ${ }^{\mathrm{b}}$ Faculty of Manufacturing Engineering, Technical University of Malaysia Malacca, Malaysia \\ ${ }^{\mathrm{c} I n s t i t u t e}$ of Mathematical Sciences, University of Malaya, Malaysia \\ mohamed.khaled@nottingham.edu.my
}

Received: January 27, 2021. Revised: March 12, 2021. Accepted: March 16, 2021. Published: March $22,2021$.

\begin{abstract}
This paper considers the hierarchical production planning (HPP) concept to solve a production planning problem in the process industry in a fuzzy environment. The adopted fuzzy HPP consists of two levels in which a fuzzy aggregate production planning (FAPP) model is developed in the first level, and then a fuzzy disaggregate production planning (FDPP) model is developed at the second level. The FAPP was reported by Omar et al. [1] and therefore, this research paper discusses the FDPP model. We formulated the disaggregate model as a fuzzy mixed-integer linear programming model that aims to develop a master production schedule in which numbers of optimal batches are developed in presence of setup time. In addition, we evaluate the performance of the FMILP by comparing its results with a previously reported approach. The findings indicate that significant cost savings were achieved by adopting the fuzzy mathematical programming approach.
\end{abstract}

Keywords - hierarchical production planning; fuzzy mathematical programming; disaggregation production planning.

\section{INTRODUCTION}

Recently, fuzzy mathematical programming approach has been employed extensively as a means to enhance the decisionmaking process in a real-world industrial problem that typically fuzzy in nature. One of the fields that has been benefiting from the employing fuzzy mathematical programming is the production planning and scheduling [2]. Production planning and scheduling are complicated tasks, which involve multiple functional units in an organization to develop an efficient decision plan for the upcoming period, in which the parameters like market demand, available resources and related operating costs are not known precisely, that is to say, uncertain or fuzzy. The term 'fuzzy' that used in this paper means either the constraints and goals are linguistically formulated or a lack of knowledge of the parameter values involved. Based on the studies of the literature, fuzzy set theory is the most-used approach to tackle the fuzziness issue that appears in a practical problem. A fuzzy set is an extension of classical (crisp) set theory to define an element without sharp boundaries. Bellman and Zadeh [3] first introduced the fuzzy sets theory in solving a problem under uncertain environment. Since then, numerous interactive and non-interactive fuzzy mathematical programming approaches have been developed to solve a real optimization problem in industry.
Basically, there are two approaches available to solve production planning and scheduling problems. The first is a monolithic approach that determines planning and scheduling decisions in a single level for the entire planning horizon, making it extremely hard to obtain optimal solutions for practical planning problems. The second is a hierarchical approach which reduces the problem complexity by partitions the planning process into a sub-problem that corresponds to different hierarchical levels of the manufacturing system and solved sequentially. Hax and Meal [4] initiated the idea of the hierarchical approach and contributed to the application of the hierarchical production planning by proposing a four-level hierarchy structure.

Most of the hierarchical production planning (HPP) structure consists of decision making at two levels, which is aggregate planning and disaggregation. Aggregate production planning is a medium-term process of determining the production, inventory, backorder and workforce levels required to meet the aggregate market demands of multiple product types. At this level, a product type with similar product cost structures and seasonal demand pattern are grouped into one product family. Once aggregate demand is satisfied, the disaggregation planning determines the quantities of the product group should be allocated to the individual products to satisfy the detailed demand known as master production schedule (MPS) for a few months. Moreover, Leong et al. [5] state that the key to any disaggregate model is to ensure that the production quantities determine in the model agree with those dictated by the aggregate model. This is the formal link that is required between the aggregate and disaggregate models. The fact that forcing the disaggregate model to fulfill the APP's results may lead to infeasibility issue. Literatures that specifically address on HPP with uncertainties are Gfrerer and Zapfel [6], Kira et al. [7], $\mathrm{Wu}$ and Ierapetritou [8], Aminloei and Ghaderi [9] and Torabi et al. [10].

In this paper, a fuzzy mixed integer linear programming (FMILP) model is developed to disaggregate the APP plan previously published by Omar et al. [1]. The proposed model intends to convert the production level of product groups into optimal batch numbers by adopting fuzzy mathematical programming approach. Most of the published work focuses on fuzzy aggregate production planning, but, in real-life industry situations, the aggregate plans have to be disaggregated to develop the master production schedules (MPS). Therefore, it 
is motivating to investigate and contribute to knowledge by studying and developing methods that able to disaggregate fuzzy aggregate production planning (FAPP).

This paper is organized as follows. Section II presents the mathematical model for the fuzzy disaggregation production planning. Section III discusses the solution procedure to develop the master production schedule, section IV reports on the results and the discussions. Finally, conclusions are presented in Section V.

\section{MODEL FORMULATION}

In this section, the model formulation of disaggregation level is presented. To mention with, the hierarchical structure of our study consists of decision making at two levels. At the top level of the hierarchy, the approach deploys a fuzzy mixedinteger linear programming model to solve the aggregate plans where setups occur. As a result, the aggregate plan provides the overall level of production; inventory and backorder of five product families (see Omar et al. [1]). Consequently, this aggregate plan must be disaggregated into detailed production plan to determine the specific quantities of the individual product to produce in real. A fuzzy mixed integer linear programming (FMILP) model is now developed at the second level. The proposed FMILP model aims to minimize the sum of production, setup, inventory and backorder cost. The inputs to disaggregation process include goal targets set by the aggregate planning and the demand of individual items. The indices, parameters and decision variables are presented next. The sign ' $\sim$ ' and ' $\wedge$ ' indicates the fuzzy constraint and parameter.

\section{Indices}

$t$

$i$

$l \quad$ production line: $1, \ldots, L$

$k \quad$ item: $1, \ldots, K$

Input from the fuzzy aggregate production planning model

$x_{i t l} \quad$ production level of product family $i$ in line $l$ in period $t$

$h_{i t} \quad$ inventory level of product family $i$ in period $t$

$b_{i t} \quad$ backorder level of product family $i$ in period $t$

$s_{t} \quad$ time consumed in set-up activities in period $t$, $s_{t}=\sum_{i=1}^{N} \sum_{l=1}^{L} G_{i} \phi_{i t l}$

\section{Parameters}

$\hat{Q}_{t l} \quad$ production capacity available for production line $l$ in period $t$

$\hat{D}_{k i t} \quad$ demand for item $k$ of product family $i$ in period $t$

$S C_{t} \quad$ maximum storage capacity in period $t$

$\hat{T} R_{t} \quad$ total regular time available in period $t$
$P_{k i}^{\min } \quad$ minimum batch size of item $k$ of product family $i$

$P_{k i}^{\max } \quad$ maximum batch size of item $k$ of product family $i$

$\hat{H} B_{k i l}$ processing hours per batch of item $k$ of product family $i$ in line $l$

\section{Decision variables}

$x_{k i t l} \quad$ production level of item $k$ of product family $i$ in line $l$ in period $t$

$h_{k i t} \quad$ inventory level of item $k$ of product family $i$ in period $t$

$b_{k i t} \quad$ backorder level of item $k$ of product family $i$ in period $t$

$\eta_{k i t l}$ integer variable denoting the number of batches of item $k$ of product family $i$ produced in line $l$ in period $t$

$S_{t} \quad$ time consumed in set-up activities in period $t$, $s_{t}=\sum_{i=1}^{N} \sum_{l=1}^{L} G_{i} \eta_{i t l}$

$w_{t} \quad$ time consumed in production activities in period $t$, $w_{t}=\sum_{i=1}^{N} \sum_{l=1}^{L} \hat{A}_{i} x_{i t l}$

Objective function

$$
\begin{gathered}
\operatorname{Min} \sum_{k=1}^{K} \sum_{i=1}^{N} \sum_{t=1}^{T} \sum_{l=1}^{L}\left(Z_{k i t} X_{k i t l}+V_{k i t} \eta_{k i t l}\right)+ \\
\sum_{k=1}^{K} \sum_{i=1}^{N} \sum_{t=1}^{T}\left(H_{k i t} h_{k i t}+C B_{k i t} b_{k i t}\right)
\end{gathered}
$$

Subject to:

$$
\begin{array}{ll}
\sum_{t=1}^{T} \sum_{k=1}^{K} x_{k i t l} \cong x_{i 1 l} & \forall_{i, l} \\
\sum_{t=1}^{T} \sum_{k=1}^{K} h_{k i t} \cong h_{i l} & \forall_{i} \\
\sum_{t=1}^{T} \sum_{k=1}^{K} b_{k i t} \cong b_{i l} & \forall_{i} \\
\sum_{l=1}^{L} x_{k i t l}+h_{k i, t-1}-b_{k i, t-1}-h_{k i t} & +b_{k i t} \cong \hat{D}_{k i t} \forall_{k, i, t} \\
\sum_{k=1}^{K} \sum_{i=1}^{N} h_{k i t} \leq S C_{t} & \forall_{t} \\
\sum_{k=1}^{K} \sum_{i=1}^{N} x_{k i t l} \simeq \hat{Q}_{t l} & \forall_{t, l} \\
x_{k i t l} \geq P_{i}^{\text {min }} \eta_{k i t l} & \forall_{i, t, l} \\
x_{k i t l} \leq M_{i} \eta_{k i t l} & \forall_{k, i, t, l} \\
\sum_{k=1}^{K} \sum_{i=1}^{N} \sum_{l=1}^{L}\left(H B_{k i l} \eta_{k i t l}\right)+s_{t} \leq \hat{T R}_{t} & \forall_{t} \\
x_{k i t l}=0 \text { for } l=1 \text { and } i>3, & k>18
\end{array}
$$


The objective function of the model is to minimize the total production, setup, inventory and backorder costs. Contrasting with the fuzzy aggregate production planning, all the cost coefficients in the objective function are assumed to be crisp values. This notion is applicable for disaggregation level since it is possible to determine the related cost parameter precisely in a short planning horizon. Equations (2), (3) and (4) represent the addition for each of the productions; inventory and backorder level at the detailed plan should be essentially equal to the planned aggregate quantities. These fuzzy constraints imply that all parameters in the left-hand side could be greater than or less than the right-hand side within an identified tolerance limit. Equation (5) is the sum of production, inventory and backorder levels is essentially equal to the imprecise demand. Equation (6) enforces the available storage capacity. Equation (7) ensures the production level for each production line essentially less than or equal to the total production capacity available. Equations (8) and (9) determine the number of batches and ensure that the monthly production quantities of the end items are within minimum and maximum batch size. Equation (10) ensures that the total batch processing time, and the setup time incurred essentially less than or equal to total available time. Equation (11) makes sure that items in family 4 and 5 are not allowed to produce in production line 2 . Similarly, as FAPP formulation, the production capacity and total regular time available in right-hand sides of equation (7) and (10) at this detailed level are still assumed to be imprecise. Finally, equation (12) is the non-negativity constraint.

\section{SOLUTION METHODOLOGY}

In this section of paper, we present the solution procedure of the proposed FMILP model to develop the MPS. There are two stages for solving the FMILP problem as below:

1) applying an appropriate approach to transform the FMILP model into its equivalent crisp model.

2) solving the crisp model as an ordinary linear programming model.

\section{A. Transform the soft constraints}

As indicated in section 2, the FMILP formulation consists of six constraints that involve with the soft equalities or inequalities relationship. In order to convert these fuzzy constraints into a crisp constraint, we first define all imprecise parameters with triangular possibility distribution as follows;

$$
\begin{aligned}
& \hat{D}_{k i t}=\left(D_{k i t}^{p}, D_{k i t}^{m}, D_{k i t}^{o}\right) \\
& \hat{Q}_{t l}=\left(Q_{t l}^{p}, Q_{t l}^{m}, Q_{t l}^{o}\right) \\
& \hat{T} R_{t}=\left(T R_{t}^{p}, T R_{t}^{m}, T R_{t}^{o}\right)
\end{aligned}
$$

$$
\begin{gathered}
\forall_{k, i, t} \\
\forall_{t, l} \\
\forall_{t}
\end{gathered}
$$

where parameter with superscript $p$ signify the most pessimistic value, $m$ is the most possible value and $o$ is the most optimistic value. This type of possibility distribution is adopted due to ease in defining the maximum and minimum limit of deviation of an imprecise value from its central value [11]. Besides, the linear membership function is used to represent the fuzzy constraint. Among the various types of membership function, linear membership function is the most applied in the literature. The linear membership function for fuzzy constraints $(A X)_{i} \widetilde{\leq} b_{i}$ and $(A X)_{i} \cong b_{i}$ are given as follows.

$$
\begin{gathered}
\mu_{i}(A X)=\left\{\begin{array}{ccc}
1 & \text { if } & (A X)_{i} \leq p_{i} \\
1-\frac{(A X)_{i}-b_{i}}{p_{i}} & \text { if } & b_{i} \leq(A X)_{i} \leq b_{i}+p_{i} \\
0 & \text { if } & (A X)_{i} \geq b_{i}+p_{i}
\end{array}\right. \\
\mu_{i}(A X)=\left\{\begin{array}{ccc}
0 & \text { if } & (A X)_{i} \leq b_{i}-p_{i} \\
1-\frac{b_{i}-(A X)_{i}}{p_{i}} & \text { if } & b_{i}-p_{i} \leq(A X)_{i} \leq b_{i} \\
1-\frac{(A X)_{i}-b_{i}}{p_{i}} & \text { if } & b_{i} \leq(A X)_{i} \leq b_{i}+p_{i} \\
0 & \text { if } & (A X)_{i} \geq b_{i}+p_{i}
\end{array}\right.
\end{gathered}
$$

where $p_{i}$ is maximum allowable violation from the aspiration level $b_{i}$.

Let $\alpha$ be the minimal acceptable level of satisfaction of fuzzy constraint, thus, the equation (2) to (4) are converted into crisp constraints as follows:

$$
\begin{array}{ll}
\sum_{t=1}^{T} \sum_{k=1}^{K} x_{k i t l} \leq x_{i 1 l}+(1-\alpha) p_{i 1 l}^{1} & \forall_{i, l} \\
\sum_{t=1}^{T} \sum_{k=1}^{K} x_{k i t l} \geq x_{i 1 l}-(1-\alpha) p_{i 1 l}^{1} & \forall_{i, l} \\
\sum_{t=1}^{T} \sum_{k=1}^{K} h_{k i t} \leq h_{i l}+(1-\alpha) p_{i l}^{2} & \forall_{i} \\
\sum_{t=1}^{T} \sum_{k=1}^{K} h_{k i t} \geq h_{i l}-(1-\alpha) p_{i l}^{2} & \forall_{i} \\
\sum_{t=1}^{T} \sum_{k=1}^{K} b_{k i t} \leq b_{i l}+(1-\alpha) p_{i l}^{3} & \forall_{i} \\
\sum_{t=1}^{T} \sum_{k=1}^{K} b_{k i t} \geq b_{i l}-(1-\alpha) p_{i l}^{3} & \forall_{i}
\end{array}
$$

In equation (5), (7) and (10), there are fuzzy constraints with imprecise right-hand side. The weighted average method proposed by Lai and Hwang [12] is adopted to convert these fuzzy constraints into their crisp ones. Let $\beta$ be the minimal acceptable possibility level of occurrence of imprecise $\hat{D}_{k i t}, \hat{Q}_{t l}, \hat{T} R_{t}$, so, the equivalent crisp constraints are now represented in the following way.

$$
\begin{aligned}
& \sum_{l=1}^{L} x_{k i t l}+h_{k i, t-1}-b_{k i, t-1}-h_{k i t}+b_{k i t} \\
& \quad \geq w_{1} D_{k i t, \beta}^{p}+w_{2} D_{k i t, \beta}^{m}+w_{3} D_{k i t, \beta}^{o}-(1-\alpha) p_{k i t}^{4} \quad \forall_{i, t}
\end{aligned}
$$

$$
\begin{aligned}
& \sum_{l=1}^{L} x_{k i t l}+h_{k i, t-1}-b_{k i, t-1}-h_{k i t}+b_{k i t} \\
& \leq w_{1} D_{k i t, \beta}^{p}+w_{2} D_{k i t, \beta}^{m}+w_{3} D_{k i t, \beta}^{o}+(1-\alpha) p_{k i t}^{4} \quad \forall_{i, t}
\end{aligned}
$$




$$
\begin{aligned}
& \sum_{k=1}^{K} \sum_{i=1}^{N} x_{k i t l} \leq w_{1} Q_{t l, \beta}^{p}+w_{2} Q_{t l, \beta}^{m}+w_{3} Q_{t l, \beta}^{o}+(1-\alpha) p_{t l}^{5} \\
& \forall_{t, l} \\
& \sum_{k=1}^{K} \sum_{i=1}^{N} \sum_{l=1_{t}}^{L}\left(H B_{k i l} \eta_{k i t l}\right)+s_{t} \\
& \quad \leq w_{1} T R_{t, \beta}^{p}+w_{2} T R_{t, \beta}^{m}+w_{3} T R_{t, \beta}^{o}+(1-\alpha) p_{t, \beta}^{6} \forall_{t}
\end{aligned}
$$

where $w_{1}+w_{2}+w_{3}=1, w_{1}, w_{2}, w_{3}$ represent the weights of pessimistic, possible and optimistic values, respectively.

\section{B. Solving the auxiliary mixed integer linear programming}

In the previous section, the FMILP model has been transformed into a mixed integer linear programming (MILP) model. Therefore, the MILP model can be directly solved as a linear programming model. LINGO 11.0 was used to develop the code and solved the model, while Microsoft Excel was used to export and import input data and solutions. In our experiments, tolerance of each fuzzy constraint is assumed to be $25 \%$, and the lower and upper bound values of the fuzzy parameters are agreed at $75 \%$ and $125 \%$ of particular crisp value, respectively. The weights of possible, pessimistic and optimistic value were fixed by way of Lai and Hwang [12].

$$
w_{1}=1 / 6, w_{2}=2 / 3, w_{3}=1 / 6
$$

Then, a computational experiment was conducted with the aim to develop an MPS with numbers of optimal batches.

\section{RESULTS AND DISCUSSIONS}

This paper focuses on disaggregation of an aggregate production planning model to create a master production schedule for a resin manufacturing plant under uncertain environment. The MPS was formulated as fuzzy mixed integer linear programing (FMILP) model that consists of fuzzy constraints and fuzzy parameters as part of the model. To investigate the benefits of using the FMILP approach to develop MPS, we compared the results of the FMILP with the mixed integer goal linear programming (MIGLP) previously reported by Omar and Teo [13]. Both models were run for 6 months and compared the FMILP, MIGILP and the company results. It is worth mentioning that originally the company had no formal planning and completely rely on non-optimization tools to develop their MPS. Table I was created to show the results of the comparison based on the cost and using monetary units (MU). Table I reveal that the previously used approach (MIGLP) could reduce the production cost by about $9.2 \%$, the inventory cost by about $86.9 \%$ and eliminate the backorder costs completely. On the other hand, using the FMILP approach to develop the MPS a further reduction of the costs is achieved. As seen in Table I, the costs of production and inventory are reduced by $28.7 \%$ and $95 \%$ respectively compared with the company costs. In addition, the FMILP also completely eliminates the backorders by fulfilment of the all the demand from production and inventory. Another important issue is revealed by studying Table I is the fact that the FMILP over performed the MIGLP in terms of cost savings. This is true since a reduction of about $21 \%$ and $61 \%$ are the differences for the production and inventory costs if the FMILP approach is used instead of the MIGLP. Therefore, the FMILP can provide smoother MPS plans and accurately utilize the resources to fulfil the demands required by the customers.

Comparing the optimal results from both models (Table II and III), we see that FHPP produced very small percentage of differences for each the decision variables (production, inventory and backorder). However, the disaggregate production planning (DPP) model for the HPP obtained high percentage of differences in the inventory variable of about $57 \%$. In terms of consistency of decision in a two-level structure, the FHPP gives significantly better results than HPP model..

Determining the number of batches for the production run to satisfy customers' demands is a complicated task. As seen in Table IV the FMILP has successfully converted the production quantities into a workable number of optimal batches that the planners can easily understand and work with.

In addition, we developed Table $\mathrm{V}$ that shows the performance of the proposed FMILP. The data was collected for a six-month MPS and as seen in Table V it takes very little time to find an optimal solution. Having said that, it is worth noting that infeasibility problem may occur when attempting to solve the MPS. This is due to constraints 2, 3 and 4 in which the right hand sides of these constraints are obtained from an optimal aggregate production planning. Bitran and Tirupati [14] recommended several ways to methods that can be used to solve the infeasibility.

\section{CONCLUSIONS}

This paper considers the results reported by Omar et al. [1] in which a fuzzy aggregate production planning model as developed and tested. The developed FAPP is disaggregated using FMILP approach to create a MPS. The paper provided details of the formulation and the solution approach for developing the MPS. Our formulation considers fuzzy constraints and fuzzy parameter that modeled by linear membership function and triangular possibility distribution. Assuming values of $\alpha=0.55$ and $\beta=0.5$, the FMILP model is transformed into an ordinary linear programming problem. To validate the proposed model, we test on different scenarios until the feasible and optimal solution is obtained. Although disaggregate level having harder constraints than the aggregate level, the FMILP managed to generate an optimal production plan. The performance of the FMILP was tested by comparing its results with a previously reported approach in [13]. The results of the comparison indicate that using the FMILP to develop the MPS have resulted in substantial savings indicating the benefits of adopting the fuzzy modeling approach. In addition, the authors highlighted the infeasibility issue a common problem when using the hierarchical approach.

The authors recommend the developing of a three-level FHPP model by adding the job sequencing model with earliness and tardiness penalties and set-up time constraint as a future research. Also the consideration of studying the effectiveness of other types of membership functions could be an interesting future research. 


\section{ACKNOWLEDGMENT}

This research is supported by the Ministry of Higher Education (MOHE), Malaysia and the Technical University of Malaysia Malacca, Malaysia.

\section{REFERENCES}

[1] Mohamed K. Omar, M. Mohd Jusoh, M. Omar, "Investigating the benefits of fuzzy mathematical programming approach for solving aggregate production planning", in Proc. IEEE World Congress on Computational Intelligence, WCCI 2012, Brisbane, Australia.

[2] J. Mula, R. Poler, J. P. Garcia-Sabater, and F. C. Lario, "Models for production planning under uncertainty: a review," International Journal of Production Economics, vol. 103, pp. 271-285, 2006.

[3] R. E. Bellman and L.A. Zadeh, "Decision-making in a fuzzy environment", Management Science, vol. 17, pp. 141-164, 1970.

[4] A. C. Hax and H. C. Meal, "Hierarchical integration of production planning and scheduling. In M.A Geisler (Ed.), Studies In Management Science (North-Holland), pp. 1-19, 1975.

[5] G. K. Leong, M. D. Olitt, M.D., and R. E. Markland, "Improved Hierarchical Production Planning," Journal Of Operations Management, vol. 8, pp. 90-114, 1989.

[6] H. Gfrerer and G. Zapfel, "Hierarchical model for production planning in the case of uncertain demand", European Journal of Operation Research, vol. 86, pp. 142-161, 1995.
[7] D. Kira, M. Kusi and I. Rakita, "A stochastic linear programming approach to hierarchical production planning", Journal of the Operational Research Society, vol. 48, pp. 207-211, 1997.

[8] D. Wu and M. Ierapetritou, "Hierarchical approach for production planning and scheduling under uncertainty", Chemical Engineering and Processing, vol. 46, pp. 1129-1140, 2007.

[9] R. T. Aminloei and S. F. Ghaderi, "Generation planning in Iranian power plants with fuzzy hierarchical production planning", Energy Conversion and Management, vol. 51, pp. 1230-1241, 2010.

[10] S. A. Torabi, M. Ebadian, R. Tanha, "Fuzzy hierarchical production planning (with a case study)", Fuzzy Sets and Systems, vol. 161, pp. $1511-1529,2010$

[11] T. F. Liang, H. W. Cheng, P. Y. Chen, and K. H. Shen, "Application of fuzzy sets to aggregate production planning with multiproducts and multitime periods", IEEE Transactions on Fuzzy Systems, vol. 19, no. 3, pp. 465-477, 2011.

[12] Y. J. Lai and C. L. Hwang, "A new approach to some possibilistic linear programming problems", Fuzzy Sets and Systems, vol. 49, pp. 121-133, 1992.

[13] Mohamed K. Omar and S. C. Teo, "Hierarchical production planning and scheduling in a multi-product, batch process environment", International Journal of Production Research, vol. 45, pp. 1029-1047, 2007.

[14] G. R. Bitran and D. Tirupati, "Hierarchical production planning", Working paper, Sloan School of Management, Massachusetts Institute of Technology, pp. 1-62, May 1989.

\section{Creative Commons Attribution License 4.0 (Attribution 4.0 International, CC BY 4.0)}

This article is published under the terms of the Creative Commons Attribution License 4.0

https://creativecommons.org/licenses/by/4.0/deed.en_US

TABLE I. COST COMPARISON OF MIGLP (DETERMINISTIC) AND FMILP (FUZZY) MODEL'S RESULTS WITH THE COMPANY'S ACTUAL PERFORMANCE

\begin{tabular}{|c|c|c|c|c|}
\hline Model & $\begin{array}{c}\text { Production Cost } \\
\text { (MU) }\end{array}$ & $\begin{array}{c}\text { Inventory Cost } \\
\text { (MU) }\end{array}$ & $\begin{array}{c}\text { Backorder Cost } \\
\text { (MU) }\end{array}$ & $\begin{array}{c}\text { Total Cost } \\
\text { (MU) }\end{array}$ \\
\hline Company & $16,579,818$ & $1,016,170$ & 57,069 & $17,653,057$ \\
\hline MIGLP & $15,054,869$ & 132,674 & 0 & $15,187,543$ \\
\hline FMILP & $11,819,293$ & 51,249 & 0 & $11,870,541$ \\
\hline \% difference of MIGLP & $9.2 \%$ & $86.9 \%$ & $100.0 \%$ & $14.0 \%$ \\
\hline \% difference of FMILP & $28.7 \%$ & $95.0 \%$ & $100.0 \%$ & $32.8 \%$ \\
\hline
\end{tabular}

TABLE II. FUZZY HIERARCHICAL PRODUCTION PLANNING RESULTS

\begin{tabular}{|c|c|c|c|c|}
\hline & $\begin{array}{c}\text { Total demand } \\
\mathbf{( K g})\end{array}$ & $\begin{array}{c}\text { Total production } \\
(\mathbf{K g})\end{array}$ & $\begin{array}{c}\text { Total inventory } \\
(\mathbf{K g})\end{array}$ & $\begin{array}{c}\text { Total backorder } \\
\mathbf{( K g})\end{array}$ \\
\hline FAPP & $5,550,905$ & $4,014,129$ & 131,455 & 0 \\
\hline FDPP & $5,550,905$ & $3,994,515$ & 136,607 & 0 \\
\hline$\%$ of differences & $0 \%$ & $0.50 \%$ & $3.80 \%$ & $0 \%$ \\
\hline
\end{tabular}


TABLE III. HIERARCHICAL PRODUCTION PLANNING RESULTS

\begin{tabular}{|c|c|c|c|c|}
\hline & $\begin{array}{c}\text { Total demand } \\
(\mathbf{K g})\end{array}$ & $\begin{array}{c}\text { Total production } \\
(\mathbf{K g})\end{array}$ & $\begin{array}{c}\text { Total inventory } \\
(\mathbf{K g})\end{array}$ & $\begin{array}{c}\text { Total backorder } \\
\mathbf{( K g )}\end{array}$ \\
\hline APP & $5,550,905$ & $4,640,001$ & 176,082 & 0 \\
\hline DPP & $5,550,905$ & $4,631,880$ & 412,117 & 0 \\
\hline$\%$ of differences & $0 \%$ & $0.20 \%$ & $57.00 \%$ & $0 \%$ \\
\hline
\end{tabular}

TABLE IV. NUMBER OF BATCHES FOR MONTH JAN - JUNE

\begin{tabular}{|c|c|c|c|c|c|c|c|c|c|c|c|c|c|}
\hline \multirow[b]{2}{*}{ Family } & \multirow[b]{2}{*}{ Item } & \multicolumn{2}{|c|}{ Jan } & \multicolumn{2}{|c|}{ Feb } & \multicolumn{2}{|c|}{ Mar } & \multicolumn{2}{|c|}{ Apr } & \multicolumn{2}{|c|}{ May } & \multicolumn{2}{|c|}{ Jun } \\
\hline & & $\mathrm{L} 1$ & $\mathrm{~L} 2$ & $\mathrm{~L} 1$ & $\mathrm{~L} 2$ & L1 & $\mathrm{L} 2$ & L1 & $\mathrm{L} 2$ & $\mathrm{~L} 1$ & $\mathrm{~L} 2$ & $\mathrm{~L} 1$ & $\mathrm{~L} 2$ \\
\hline \multirow[t]{10}{*}{ Family 1} & 1 & 0 & 0 & 8 & 0 & 17 & 8 & 11 & 0 & 4 & 0 & 1 & 0 \\
\hline & 2 & 0 & 0 & 3 & 0 & 5 & 0 & 5 & 3 & 6 & 0 & 8 & 0 \\
\hline & 3 & 0 & 0 & 3 & 0 & 3 & 0 & 2 & 0 & 2 & 0 & 3 & 0 \\
\hline & 4 & 0 & 0 & 3 & 0 & 5 & 0 & 3 & 0 & 5 & 0 & 2 & 0 \\
\hline & 5 & 0 & 0 & 2 & 0 & 3 & 0 & 4 & 0 & 3 & 0 & 3 & 0 \\
\hline & 6 & 1 & 0 & 0 & 0 & 0 & 0 & 0 & 0 & 0 & 0 & 3 & 0 \\
\hline & 7 & 0 & 0 & 0 & 0 & 0 & 0 & 3 & 0 & 2 & 0 & 2 & 0 \\
\hline & 8 & 0 & 0 & 1 & 0 & 1 & 0 & 1 & 0 & 2 & 0 & 1 & 0 \\
\hline & 9 & 0 & 0 & 1 & 0 & 1 & 0 & 1 & 0 & 1 & 0 & 1 & 0 \\
\hline & 10 & 0 & 0 & 5 & 0 & 4 & 0 & 14 & 0 & 6 & 0 & 6 & 0 \\
\hline \multirow[t]{6}{*}{ Family 2} & 11 & 0 & 0 & 2 & 0 & 0 & 2 & 0 & 1 & 0 & 2 & 0 & 2 \\
\hline & 12 & 0 & 0 & 0 & 0 & 0 & 0 & 0 & 0 & 0 & 0 & 0 & 0 \\
\hline & 13 & 0 & 0 & 2 & 0 & 0 & 2 & 0 & 1 & 0 & 1 & 0 & 1 \\
\hline & 14 & 0 & 0 & 1 & 0 & 0 & 1 & 0 & 1 & 0 & 1 & 0 & 1 \\
\hline & 15 & 0 & 0 & 2 & 0 & 0 & 3 & 0 & 4 & 0 & 5 & 0 & 3 \\
\hline & 16 & 0 & 0 & 0 & 0 & 0 & 3 & 0 & 3 & 0 & 3 & 0 & 4 \\
\hline \multirow[t]{2}{*}{ Family 3} & 17 & 0 & 0 & 3 & 0 & 0 & 2 & 2 & 0 & 0 & 1 & 2 & 0 \\
\hline & 18 & 5 & 0 & 1 & 0 & 0 & 1 & 1 & 0 & 0 & 2 & 1 & 0 \\
\hline Family 4 & 19 & 0 & 2 & 0 & 0 & 0 & 2 & 0 & 0 & 0 & 2 & 0 & 0 \\
\hline \multirow[t]{2}{*}{ Family 5} & 20 & 0 & 0 & 0 & 1 & 0 & 0 & 0 & 3 & 0 & 0 & 0 & 2 \\
\hline & $\begin{array}{l}\text { Total of } \\
\text { batches }\end{array}$ & 6 & 2 & 36 & 1 & 40 & 24 & 46 & 18 & 32 & 16 & 34 & 13 \\
\hline
\end{tabular}

TABLE V. COMPUTATIONAL EFFICIENCY OF FMILP MODEL

\begin{tabular}{|c|c|c|c|c|c|}
\hline Model & Variables & Integer & Constraint & Non-zero & Time (seconds) \\
\hline FMILP & 1924 & 280 & 955 & 4368 & 0.05 \\
\hline
\end{tabular}

